Vol. 1, No. 1, Januari 2019

\title{
SURVEI SARANA KESEHATAN LINGKUNGAN MASYARAKAT DESA KRAMAT KECAMATAN TAPA KABUPATEN BONE BOLANGO
}

\section{Survey of Environmental Health Facilities Kramat Village Communities Tapa District, Regency of Bone Bolango}

\author{
Lia Amalia \\ Jurusan Kesehatan Masyarakat, FOK UNG, Gorontalo \\ e-mail: lia.amalia29@gmail.com
}

\begin{abstract}
Abstrak
Jumlah penduduk yang terus bertambah berdampak pada bertambahnya kebutuhan sarana kesehatan termasuk sarana kesehatan lingkungan, seperti jamban, Sarana Pembuangan air Limbah (SPAL), tempat sampah dan Sumber Air Bersih. Hasil Riskesdas 2013 proporsi rumah tangga berdasarkan penggunaan fasilitas buang air besar, rerata nasional perilaku buang air besar di jamban (82,6\%) dan provinsi Gorontalo 77,5\%. Untuk penampungan air limbah RT, hanya 15,5\% yang menggunakan penampungan tertutup (SPAL) proporsi rumah tangga yang memiliki akses sumber air minum adalah $66,8 \%$. Tujuan penelitian adalah mengetahui sarana kesehatan lingkungan pada masyarakat Desa Kramat berdasarkan kepemilikan jamban, sarana pembuangan air limbah, kepemilikan tempat sampah dan sumber air bersih. Jenis penelitian adalah survey observasional dengan pendekatan deskriptif. Penelitian dilakukan di Desa Kramat, Kecamatan Tapa Kabupaten Bone Bolango. Tehnik pengumpulan data dilakukan dengan wawancara menggunakan kuesioner dan lembar observasi kepada seluruh kepala rumah tangga yang tinggal di Desa Kramat sebanyak 172 KK. Sarana kesehatan lingkungan pada masyarakat Desa Kramat berdasarkan kepemilikan jamban adalah 131 rumah tangga $(76,2 \%)$ yang memiliki jamban, untuk sarana pembuangan air limbah dari 172 rumah tangga, hanya 57 rumah tangga $(33,1 \%)$ yang memanfaatkan penampungan/peresapan sebagai tempat pembuangan air limbah, terdapat 116 rumah tangga (70,7\%) yang memiliki tempat pembuangan sampah dan masih terdapat sumber air bersih yang berjarak $\leq 10$ meter sebanyak 66 rumah tangga (38,0\%), disarankan agar menjalin kerjasama lintas sektoral antara pemerintah, Puskesmas dan sektor terkait lainnya dengan masyarakat untuk meningkatkan cakupan dan kesadaran masyarakat terhadap jamban keluarga, SPAL, tempat sampah dan sumber air bersih yang memenuhi syarat di Desa Kramat Kecamatan Tapa Kabupaten Bone Bolango.
\end{abstract}

Kata Kunci: Jamban keluarga; SPAL; Sumber air bersih; Tempat sampah

\section{Abstract}

The increasing population will have an impact on the increasing need for health facilities including environmental health facilities, such as latrines, Wastewater Disposal Facilities (SPAL), trash bins and Clean Water Sources. Riskesdas 2013 results on the proportion of households based on the use of defecation facilities, national average defecation behavior in latrines $(82.6 \%)$ and Gorontalo province $77.5 \%$. For households wastewater storage, only $15.5 \%$ use closed shelters (SPAL) The proportion of households that have access to drinking water sources is $66.8 \%$. This study aims to determine the environmental health facilities in Kramat Village community based on ownership of latrines, means of waste water disposal, ownership of trash bins and sources of clean water. This research used observational survey research with a descriptive approach. This study was conducted in Kramat Village, Tapa District, Regency of Bone Bolango. Data collection techniques were carried out by interviews using questionnaires and observation sheets to all household heads who lived in Kramat Village as many as 172 households. The means of environmental health for the Kramat villagers based on the ownership of latrines are 131 households $(76.2 \%)$ who have latrines, for wastewater disposal facilities from 172 households, only 57 households (33.1\%) utilize the shelter / infiltration as a wastewater disposal site, there are 116 households $(70.7 \%)$ that have garbage disposal sites and there are still sources of clean water within meter 10 meters of 66 households $(38.0 \%)$, it is recommended to establish cross-sectoral cooperation between government, Puskesmas and other related sectors with the community to increase community coverage and awareness of family latrines, SPAL, garbage bins and clean water sources that are eligible in Kramat Village, Tapa District, Bone Bolango District

Keyword : Clean water sources, Family latrines; SPAL; garbage bins. 


\section{PENDAHULUAN}

Kesehatan merupakan suatu fenomena sosial, maka disadari bahwa pelayanan kesehatan bukanlah satu-satunya faktor yang berpengaruh terhadap kesehatan masyarakat, melainkan dipengaruhi juga oleh faktor perilaku dan lingkungan, yang pengaruhnya jauh lebih besar. Salah satu faktor lingkungan yang sangat berpengaruh adalah kebiasaan masyarakat yang suka buang air besar disembarang tempat, Sarana Pembuangan Air Limbah, pengelolaan sampah dan serta penyediaan air bersih.

Adanya kebutuhan fisiologis manusia seperti memiliki rumah, yang mencakup kepemilikan jamban sebagai bagian dari kebutuhan setiap anggota keluarga, selain itu adalah penyediaan air bersih, Sarana Pembuangan Air Limbah, dan pengelolaan sampah sehingga masalah kondisi lingkungan tidak terlepas dari aspek kepemilikan terhadap sarana yang digunakan terutama dikaitkan dengan pemeliharaan dan kebersihan sarana. Jumlah penduduk yang terus bertambah akan berdampak pada konsekuensi bertambahnya kebutuhan sarana kesehatan termasuk sarana kesehatan lingkungan, seperti jamban, Sarana Pembuangan air Limbah (SPAL), tempat sampah dan Sumber Air Bersih.

Hasil Riskesdas 2013 tentang proporsi rumah tangga berdasarkan penggunaan fasilitas buang air besar, rerata nasional perilaku buang air besar di jamban (82,6\%) dan provinsi Gorontalo 77,5\%. Untuk penampungan air limbah RT, hanya 15,5\% yang menggunakan penampungan tertutup (SPAL) Proporsi rumah tangga yang memiliki akses terhadap sumber air minum adalah $66,8 \%{ }^{1}$.

Untuk penampungan air limbah RT di Indonesia umumnya dibuang langsung ke got (46,7\%). Hanya $15,5 \%$ yang menggunakan penampungan tertutup di pekarangan dengan dilengkapi SPAL, dan $13,2 \%$ menggunakan penampungan terbuka di pekarangan, dan 7,4\% ditampung di luar pekarangan. Sedangkan dalam hal pengelolaan sampah RT umumnya dilakukan dengan cara dibakar (50,1\%) dan hanya 24.9 persen yang diangkut oleh petugas. Cara lainnya dengan cara ditimbun dalam tanah, dibuat kompos, dibuang ke kali/parit/laut dan dibuang sembarangan. Lima provinsi dengan proporsi RT yang mengelola sampah dengan cara dibakar tertinggi adalah Gorontalo (79,5\%), Aceh (70,6\%), Lampung (69,9\%), Riau (66,4\%), dan Kalimantan Barat (64,3\%).

Tujuan penelitian ini adalah untuk mengetahui sarana kesehatan lingkungan pada masyarakat Desa Kramat berdasarkan kepemilikan jamban, sarana pembuangan air limbah, kepemilikan tempat sampah dan sumber air bersih.

\section{METODE PENELITIAN}

Jenis penelitian adalah penelitian survey observasional dengan pendekatan deskriptif. Penelitian dilakukan di Desa Kramat, Kecamatan Tapa Kabupaten Bone Bolango. Tehnik pengumpulan data dilakukan dengan wawancara menggunakan kuesioner dan lembar observasi kepada seluruh kepala rumah tangga yang tinggal di Desa Kramat sebanyak $172 \mathrm{KK}$. Data dalam penelitian ini dianalisis univariat menggunakan program SPSS dan disajikan dalam bentuk tabel serta digarasikan berdasarkan data dan hasil penelitian yang diperoleh.

\section{HASIL DAN PEMBAHASAN}

3.1 Hasil

Berdasarkan hasil penelitian yang dilakukan di Desa Kramat, maka diperoleh data sebagai berikut: 
Vol. 1 , No. 1 , Januari 2019

Tabel 1. Distribusi Penduduk, Jumlah Rumah Tangga dan Jumlah Kepala Keluarga Berdasarkan Dusun Di Desa Kramat Kecamatan Tapa Kabupaten Bone Bolango Tahun 2018

\begin{tabular}{ccccccc}
\hline \multirow{2}{*}{ Wilayah Desa } & \multicolumn{2}{c}{ Jumlah Jiwa } & \multicolumn{2}{c}{ Jumlah RT } & \multicolumn{2}{c}{ Jumlah KK } \\
\cline { 2 - 7 } & $\mathrm{N}$ & $\%$ & $\mathrm{n}$ & $\%$ & $\mathrm{n}$ & $\%$ \\
\hline Dusun I (Deki) & 208 & 28,9 & 49 & 28,5 & 61 & 27,9 \\
\hline Dusun II (Lipu) & 233 & 32,3 & 58 & 33,7 & 78 & 35,8 \\
\hline Dusun III (Hubulo) & 279 & 38,8 & 65 & 37,8 & 79 & 36,3 \\
\hline Jumlah & 720 & 100,0 & 172 & 100,0 & 218 & 100,0 \\
\hline
\end{tabular}

Sumber: Data Primer, 2018

3.1.1 Karakteristik Penduduk Desa Kramat

Distribusi Penduduk Berdasarkan Kelompok Umur di Desa Kramat dapat dilihat di tabel berikut:

Tabel 2. Distribusi Penduduk Berdasarkan Kelompok Umur di Desa Kramat Kecamatan Tapa Kabupaten Bone BolangoTahun 2018

\begin{tabular}{|c|c|c|c|c|c|c|c|c|}
\hline \multirow{3}{*}{$\begin{array}{l}\text { Kelompok Umur } \\
\text { (Tahun) }\end{array}$} & \multicolumn{6}{|c|}{ Dusun } & \multirow{2}{*}{\multicolumn{2}{|c|}{ Jumlah }} \\
\hline & \multicolumn{2}{|c|}{ Dusun 1} & \multicolumn{2}{|c|}{ Dusun 2} & \multicolumn{2}{|c|}{ Dusun 3} & & \\
\hline & $\mathrm{N}$ & $\%$ & $\mathrm{n}$ & $\%$ & $\mathrm{n}$ & $\%$ & $\mathrm{n}$ & $\%$ \\
\hline $0-4$ & 12 & 6,7 & 15 & 5,2 & 33 & 11,5 & 60 & 7,73 \\
\hline $5-9$ & 20 & 9,6 & 10 & 4,3 & 23 & 8,2 & 53 & 7,36 \\
\hline $10-14$ & 13 & 6,2 & 18 & 7,7 & 22 & 7,9 & 53 & 10,46 \\
\hline $15-19$ & 18 & 8,7 & 23 & 9,9 & 22 & 7,9 & 63 & 8,83 \\
\hline $20-24$ & 25 & 12,0 & 19 & 8,2 & 25 & 9,0 & 69 & 9,73 \\
\hline $25-29$ & 16 & 7,7 & 21 & 9,0 & 18 & 6,5 & 55 & 7,73 \\
\hline $30-34$ & 12 & 5,8 & 17 & 7,3 & 25 & 9,0 & 54 & 7,26 \\
\hline $35-39$ & 14 & 6,7 & 13 & 5,6 & 22 & 7,9 & 49 & 6,73 \\
\hline $40-44$ & 13 & 6,2 & 17 & 7,3 & 26 & 9,3 & 56 & 7,6 \\
\hline $45-49$ & 20 & 9,6 & 16 & 6,9 & 24 & 8,6 & 60 & 8,36 \\
\hline $50-54$ & 9 & 4,3 & 22 & 9,4 & 13 & 4,7 & 44 & 6,13 \\
\hline $55-59$ & 5 & 2,4 & 20 & 8,6 & 12 & 4,3 & 37 & 5,1 \\
\hline$\geq 60$ & 29 & 13,9 & 25 & 10,7 & 15 & 5,4 & 69 & 10,0 \\
\hline Jumlah & 208 & 28,9 & 233 & 32,4 & 279 & 38,7 & 720 & 100,0 \\
\hline
\end{tabular}

Sumber : Data Primer, 2018

Distribusi Penduduk Berdasarkan Jenis Kelamin di Desa Kramat dapat dilihat di tabel berikut:

Tabel 3. Distribusi Penduduk Berdasarkan Jenis Kelamin di Desa Kramat Kecamatan Tapa Kabupaten Bone Bolango Tahun 2018

\begin{tabular}{lcccccccc}
\hline \multirow{3}{*}{ Jenis Kelamin } & \multicolumn{9}{c}{ Dusun } & \multirow{2}{*}{ Jumlah } \\
\cline { 2 - 7 } & \multicolumn{2}{c}{ Dusun 1 } & \multicolumn{2}{c}{ Dusun 2 } & \multicolumn{2}{c}{ Dusun 3 } & & \\
\cline { 2 - 7 } & $\mathrm{N}$ & $\%$ & $\mathrm{n}$ & $\%$ & $\mathrm{n}$ & $\%$ & $\mathrm{n}$ & $\%$ \\
\hline Laki-Laki & 98 & 47,1 & 113 & 48,5 & 134 & 48,0 & 345 & 100,0 \\
\hline Perempuan & 110 & 52,9 & 120 & 51,5 & 145 & 52,0 & 375 & 100,0 \\
\hline Jumlah & 208 & 28,9 & 233 & 32,3 & 134 & 38,8 & 720 & 100,0 \\
\hline
\end{tabular}

Sumber: Data Primer, 2018 
Vol. 1 , No. 1 , Januari 2019

3.1.2 Distribusi Rumah Tangga Berdasarkan Kepemilikan Jamban

Distribusi Rumah Tangga Berdasarkan Kepemilikan Jamban di Desa Kramat dapat dilihat pada tabel berikut:

Tabel 4. Distribusi Rumah Tangga Berdasarkan Kepemilikan Jamban di Desa Kramat

Kecamatan Tapa Kabupaten Bone Bolango Tahun 2018

\begin{tabular}{ccccccccc}
\hline \multirow{2}{*}{$\begin{array}{c}\text { Kepemilikan } \\
\text { jamban }\end{array}$} & \multicolumn{9}{c}{ Dusun 1 } & \multicolumn{2}{c}{ Dusun 2 } & \multicolumn{2}{c}{ Dusun 3 } & \multirow{2}{*}{ Jumlah } \\
\cline { 2 - 8 } & $\mathrm{N}$ & $\%$ & $\mathrm{n}$ & $\%$ & $\mathrm{n}$ & $\%$ & $\mathrm{n}$ & $\%$ \\
\hline Ada & 47 & 95,9 & 48 & 82,8 & 36 & 55,4 & 131 & 76,2 \\
\hline Tidak ada & 2 & 4,1 & 10 & 17,2 & 29 & 44,6 & 41 & 23,8 \\
\hline Jumlah & 49 & 100,0 & 58 & 100,0 & 65 & 100,0 & 172 & 100,0 \\
\hline
\end{tabular}

Sumber: Data Primer, 2018

Distribusi Tempat BAB bagi Rumah Tangga Yang Tidak Memiliki Jamban di Desa Kramat dapat dilihat pada tabel berikut:

Tabel 5. Distribusi Tempat BAB bagi Rumah Tangga Yang Tidak Memiliki Jamban di Desa Kramat Kecamatan Tapa Kabuparten GorontaloTahun 2018

\begin{tabular}{ccccccccc}
\hline \multirow{2}{*}{ Tempat BAB } & \multicolumn{9}{c}{ Dusun } & \multirow{2}{*}{ Jumlah } \\
\cline { 2 - 7 } & \multicolumn{2}{c}{ Dusun 1 } & \multicolumn{2}{c}{ Dusun 2 } & \multicolumn{2}{c}{ Dusun 3} & & \\
\cline { 2 - 7 } & $\mathrm{N}$ & $\%$ & $\mathrm{n}$ & $\%$ & $\mathrm{n}$ & $\%$ & $\mathrm{n}$ & $\%$ \\
\hline Got & 2 & 100,0 & 10 & 100,0 & 12 & 41,3 & 24 & 58,5 \\
\hline WC tetangga & 0 & 0,0 & 0 & 0,0 & 10 & 34,4 & 10 & 24,3 \\
\hline WC umum & 0 & 0,0 & 0 & 0,0 & 7 & 24,1 & 7 & 17,2 \\
\hline Jumlah & 2 & 100,0 & 10 & 100,0 & 29 & 100,0 & 41 & 100,0
\end{tabular}

Sumber: Data Prime, 2018

3.1.3 Distribusi Rumah Tangga Berdasarkan Sarana Pembuangan Air Limbah

Distribusi Rumah Tangga Berdasarkan Sarana Pembuangan Air Limbah Di Desa Kramat dapat dilihat pada tabel berikut:

Tabel 6. Distribusi Rumah Tangga Berdasarkan Sarana Pembuangan Air Limbah Di Desa Kramat Kecamatan Tapa Kabupaten Bone Bolango Tahun 2018

\begin{tabular}{|c|c|c|c|c|c|c|c|c|}
\hline \multirow{3}{*}{$\begin{array}{c}\text { Sarana membuang air } \\
\text { limbah }\end{array}$} & \multicolumn{6}{|c|}{ Dusun } & \multirow{2}{*}{\multicolumn{2}{|c|}{ Jumlah }} \\
\hline & \multicolumn{2}{|c|}{ Dusun 1} & \multicolumn{2}{|c|}{ Dusun 2} & \multicolumn{2}{|c|}{ Dusun 3} & & \\
\hline & $\mathrm{N}$ & $\%$ & $\mathrm{n}$ & $\%$ & $\mathrm{n}$ & $\%$ & $\mathrm{n}$ & $\%$ \\
\hline Penampungan/peresapan & 18 & 36,7 & 26 & 44,8 & 13 & 20,0 & 57 & 33,1 \\
\hline Dialirkan ke got & 30 & 61,3 & 12 & 20,7 & 30 & 46,2 & 72 & 41,8 \\
\hline Dialirkan ke sawah/kebun & 0 & 0,0 & 4 & 6,9 & 1 & 1.5 & 5 & 2,9 \\
\hline Dialirkan ke sungai/pantai & 0 & 0,0 & 5 & 8,6 & 12 & 18,5 & 17 & 9,9 \\
\hline $\begin{array}{l}\text { Dialirkan ke sekitar } \\
\text { rumah }\end{array}$ & 1 & 2,0 & 11 & 19,0 & 9 & 13,8 & 21 & 12,3 \\
\hline Jumlah & 49 & 28,4 & 58 & 33,7 & 65 & 37,9 & 172 & 100,0 \\
\hline
\end{tabular}

Sumber: Data Primer Desa Kramat Kecamatan Tapa, Mei 2018.

3.1.4 Distribusi Rumah Tangga Berdasarkan Kepemilikan Tempat Sampah

Distribusi Rumah Tangga Berdasarkan Kepemilikan Tempat Sampah Di Desa Kramat dapat dilihat pada tabel berikut: 
Vol. 1 , No. 1 , Januari 2019

Tabel 7. Distribusi Rumah Tangga Berdasarkan Kepemilikan Tempat Sampah Di Desa Kramat Kecamatan Tapa Kabupaten Bone Bolango Tahun 2018

\begin{tabular}{|c|c|c|c|c|c|c|c|c|}
\hline \multirow{3}{*}{$\begin{array}{c}\text { Kepemilikan tempat } \\
\text { sampah }\end{array}$} & \multicolumn{6}{|c|}{ Dusun } & \multirow{2}{*}{\multicolumn{2}{|c|}{ Jumlah }} \\
\hline & \multicolumn{2}{|c|}{ Dusun 1} & \multicolumn{2}{|c|}{ Dusun 2} & \multicolumn{2}{|c|}{ Dusun 3} & & \\
\hline & $\mathrm{n}$ & $\%$ & $\mathrm{n}$ & $\%$ & $\mathrm{n}$ & $\%$ & $\mathrm{n}$ & $\%$ \\
\hline Ada & 46 & 93,9 & 56 & 96,6 & 14 & 21,5 & 116 & 70,7 \\
\hline Tidak ada & 3 & 6,1 & 2 & 3,4 & 51 & 78,5 & 56 & 29,3 \\
\hline Jumlah & 49 & 100,0 & 58 & 100,0 & 65 & 100,0 & 172 & 100,0 \\
\hline
\end{tabular}

Sumber: Data Primer, 2018

Distribusi Rumah Tangga Berdasarkan Proses Pengelolaan Sampah Di Desa Kramat dapat dilihat pada tabel berikut:

Tabel 8. Distribusi Rumah Tangga Berdasarkan Proses Pengelolaan Sampah di Desa Kramat Kecamatan Tapa Kabupaten Bone Bolango Tahun 2018

\begin{tabular}{|c|c|c|c|c|c|c|c|c|}
\hline \multirow{3}{*}{$\begin{array}{l}\text { Proses pengolahan } \\
\text { sampah }\end{array}$} & \multicolumn{6}{|c|}{ Dusun } & \multirow{2}{*}{\multicolumn{2}{|c|}{ Jumlah }} \\
\hline & \multicolumn{2}{|c|}{ Dusun 1} & \multicolumn{2}{|c|}{ Dusun 2} & \multicolumn{2}{|c|}{ Dusun 3} & & \\
\hline & $\mathrm{n}$ & $\%$ & $\mathrm{n}$ & $\%$ & $\mathrm{n}$ & $\%$ & $\mathrm{n}$ & $\%$ \\
\hline Dikumpulkan lalu dibakar & 42 & 85,7 & 56 & 96,5 & 14 & 21,5 & 116 & 67,4 \\
\hline $\begin{array}{c}\text { Dikumpulkan lalu } \\
\text { ditimbun }\end{array}$ & 1 & 2,0 & 2 & 3,5 & 10 & 15,3 & 13 & 7,5 \\
\hline $\begin{array}{c}\text { Dibuang } \\
\text { dikebun/sawah/tempat } \\
\text { terbuka }\end{array}$ & 2 & 4,1 & 0 & 0,0 & 10 & 15,3 & 12 & 6,9 \\
\hline Dibuang di sekitar rumah & 0 & 0,0 & 0 & 0,0 & 31 & 47,6 & 31 & 15,9 \\
\hline $\begin{array}{c}\text { Dibungkus lalu dibuang } \\
\text { ke TPA }\end{array}$ & 4 & 8,2 & 0 & 0,0 & 0 & 0,0 & 4 & 2,3 \\
\hline Jumlah & 49 & $\begin{array}{c}100 \\
0\end{array}$ & 58 & $\begin{array}{c}100 \\
0\end{array}$ & 65 & $\begin{array}{c}100 \\
0\end{array}$ & 172 & 100,0 \\
\hline
\end{tabular}

\section{Sumber: Data Primer, 2018}

3.1.5 Distribusi Rumah Tangga Berdasarkan Jarak Sumber Air Minum Dengan WC

Distribusi Rumah Tangga Berdasarkan Jarak Sumber Air Minum Dengan WC Di Desa Kramat dapat dilihat pada tabel berikut:

Tabel 9. Distribusi Rumah Tangga Berdasarkan Jarak Sumber Air Bersih Dengan WC Di Desa Kramat Kecamatan Tapa Tahun 2018

\begin{tabular}{|c|c|c|c|c|c|c|c|c|}
\hline \multirow{3}{*}{$\begin{array}{c}\text { Jarak sumber air } \\
\text { Bersih dengan } \\
\text { WC }\end{array}$} & \multicolumn{6}{|c|}{ Dusun } & \multirow{2}{*}{\multicolumn{2}{|c|}{ Jumlah }} \\
\hline & \multicolumn{2}{|c|}{ Dusun 1} & \multicolumn{2}{|c|}{ Dusun 2} & \multicolumn{2}{|c|}{ Dusun 3} & & \\
\hline & $\mathrm{N}$ & $\%$ & $\mathrm{n}$ & $\%$ & $\mathrm{n}$ & $\%$ & $\mathrm{n}$ & $\%$ \\
\hline$\leq 10 \mathrm{~m}$ & 27 & 55,1 & 50 & 86,2 & 29 & 44,6 & 106 & 61,9 \\
\hline$>10 \mathrm{~m}$ & 22 & 44,9 & 8 & 13,8 & 36 & 55,4 & 66 & 38,1 \\
\hline Jumlah & 49 & 100,0 & 58 & 100,0 & 65 & 100,0 & 172 & 100,0 \\
\hline
\end{tabular}

Sumber: Data Primer, 2018

Distribusi Rumah Tangga Berdasarkan Proses Pemasakan Air Di Desa Kramat dapat dilihat pada tabel berikut: 
Vol. 1 , No. 1 , Januari 2019

Tabel 10. Distribusi Rumah Tangga Berdasarkan Proses Pemasakan Air Di Desa

Kramat Kecamatan Tapa Kabupaten Bone Bolango Tahun 2018

\begin{tabular}{ccccccccc}
\hline \multirow{2}{*}{$\begin{array}{c}\text { Proses } \\
\text { pemasakan } \\
\text { air }\end{array}$} & \multicolumn{9}{c}{ Dusun } & \multicolumn{2}{c}{ Jumlah } \\
\cline { 2 - 8 } & \multicolumn{2}{c}{ Dusun 1} & \multicolumn{2}{c}{ Dusun 2 } & \multicolumn{2}{c}{ Dusun 3 } & & \\
\hline Ya & 43 & 87,8 & 41 & 70,7 & 55 & 84,6 & 139 & 81,1 \\
\hline Tidak & 6 & 12,2 & 17 & 29,3 & 10 & 15,4 & 33 & 18,9 \\
\hline Jumlah & 49 & 100,0 & 58 & 100,0 & 65 & 100,0 & 172 & 100,0 \\
\hline
\end{tabular}

Sumber: Data Primer, 2018

\subsection{Pembahasan}

Sumber data sekunder profil Desa Kramat tahun 2016 diperoleh data jumlah penduduk Desa Kramat sebanyak 1,265 jiwa, tetapi berdasarkan hasil pengambilan data door to door yang didapatkan jumlah jiwa yang temui sebanyak 720 jiwa dengan 172 KRT dan $218 \mathrm{KK}$ (tabel 1). Hal ini disebabkan karena pengambilan yang dilakukan tidak menyeluruh disemua rumah, ada sebagian rumah yang tidak ada penghuni ketika melakukan pendataan dan sebagian besar di Dusun 3 (Hubulo) tepatnya yang berada di Pesantren Hubulo terdapat beberapa jiwa yang tidak terdata karena akses masuk kedalam pesantren terbatas.

Pada tabel 2 dapat dilihat bahwa dari kelompok umur diperoleh data bahwa Dusun 3 (Hubulo) merupakan dusun yang paling banyak penduduk yakni 279 jiwa (38,7\%). Jumlah kelompok umur terbanyak di Desa kramat adalah umur produktif yakni umur 20-59 tahun yakni 422 jiwa $(58,6 \%)$. Pada tabel 3 dapat dilihat bahwa dari jumlah penduduk 720 jiwa, terdapat penduduk laki-laki sebanyak 345 jiwa $(47,86 \%)$ dan penduduk perempuan sebanyak 375 jiwa $(52,13 \%)$ yang tersebar di tiga. Di Dusun Deki terdapat 208 Jiwa, dimana laki-laki sebanyak 98 jiwa $(47,1 \%)$ dan perempuan sebanyak 110 jiwa (52,9\%). Di Dusun Lipu terdapat 233 jwa, dimana laki-laki sebanyak 113 jiwa (48,5\%) dan perempuan sebanyak 120 jiwa (51,5\%). Kemudian di Dusun Hubulo231 jiwa, dimana laki-laki sebanyak 134 jiwa (48,0\%) dan perempuan sebanyak 145 jiwa $(52,0 \%)$.

Berdasarkan tabel 4 dapat dilihat bahwa dari 172 rumah tangga, ada 131 rumah tangga $(76,2 \%)$ yang memiliki jamban dan yang tidak memiliki jamban sebanyak 41 rumah tangga $(23,8 \%)$, dimana dusun yang paling banyak memiliki jamban adalah Dusun 1 (Deki) sebanyak 47 rumah tangga $(95,9 \%)$ dan dusun yang paling banyak tidak memiliki jamban adalah Dusun 3 (Hubulo) sebanyak 29 rumah tangga $(44,6 \%)$. Dusun Deki menjadi dusun yang paling banyak rumah tangga memiliki jamban dikarenakan Dusun Deki adalah dusun dimana pusat pemerintahan Desa Kramat, dimana di dusun tersebut terdapat puskesmas Tapa, berada di jalan utama kecamatan dan sebagian besar masyarakatnya bekerja antara lain sebagai pegawai negeri sipil, pegawai swasta, ataupun wiraswasta. Sedangkan Dusun 3 (Hubulo) sebagian besar bekerja sebagai petani, ibu rumah tangga maupun buruh harian.

Berdasarkan tabel 5 dari 172 rumah tangga, ada 24 rumah tangga $(58,5 \%)$ yang memanfaatkan got/sungai untuk buang air besar, 10 rumah tangga (24,3\%) menggunakan WC tetangga, sementara 7 rumah tangga (17,2\%) menggunakan WC Umum, dari data tersebut memperlihatkan bahwa walaupun terdapat 41 RT yang tidak memiliki WC pribadi akan tetapi terdapat 17 RT menggunakan WC tetangga dan WC umum untuk keperluan buang air besar maupun buang air kecil walaupun masih terdapat 24 rumah tangga yang $\mathrm{BAB}$ ataupun $\mathrm{BAK}$ di got sekitaran rumah dan sungai.

Berdasarkan tabel 6 dari 172 rumah tangga, ada 57 rumah tangga $(33,1 \%)$ yang memanfaatkan penampungan/peresapan sebagai tempat pembuangan air limbah, 72 rumah tangga $(41,8 \%)$ yang dialirkan ke got, 5 rumah tangga (2,9\%) dialirkan ke sawah/kebun, 17 rumah tangga $(9,9 \%)$ dialirkan ke sungai dan 21 rumah tangga (12,3\%) yang dialirkan di sekitar rumah. 
Vol. 1 , No. 1 , Januari 2019

Sampah erat kaitannya dengan kesehatan masyarakat, karena dari sampah akan hidup berbagai mikroorganisme penyebab penyakit. Berdasarkan tabel 7 memperlihatkan bahwa dari 172 rumah tangga, ada 116 rumah tangga (70,7\%) yang memiliki Tempat Pembuangan Sampah dan ada 56 rumah tangga $(29,3 \%)$ yang tidak memiliki tempat sampah. Berdasarkan tabel 8 bahwa dari 172 rumah tangga, ada 116 rumah tangga $(67,4 \%)$ yang mengelola sampah dengan cara di kumpulkan lalu di bakar. Kemudian ada 13 rumah tangga (7,5\%) yang mengelola sampah dengan cara dikumpulkan lalu ditimbun, ada 12 rumah tangga (6,9\%) yang mengelola sampah dengan cara dibuang dikebun/semak/sawah/tempat terbuka, terdapat 31 rumah tangga $(15,9 \%)$ yang mengelola sampah dengan cara dibuang disekitar rumah, dan ada 4 rumah tangga $(2,7 \%)$ yang mengelola sampah dengan cara dibungkus lalu dibuang ke TPA.

Air sangat penting bagi kehidupan manusia. Kebutuhan manusia akan air sangat kompleks antara lain untuk minum, masak, mandi dan mencuci. Salah satu persyaratan yang harus dipenuhi dalam memenuhi kebutuhan air adalah jarak sumber air minum dengan jamban. Berdasarkan tabel 9 memperlihatkan bahwa terdapat 106 rumah tangga (61,9\%) yang memiliki jarak sumber air dengan WC yang $>10$ meter, Sedangkan jarak sumber air bersih dengan WC yang $\leq 10$ meter sebanyak 66 rumah tangga $(38,0 \%)$. Hal ini akan bisa berdampak pada kualitas air yang akan dikonsumsi masyarakat.

\section{KESIMPULAN}

Sarana kesehatan lingkungan pada masyarakat Desa Kramat berdasarkan kepemilikan jamban adalah terdapat 131 rumah tangga (76,2\%) yang memiliki jamban, untuk sarana pembuangan air limbah dari 172 rumah tangga, hanya 57 rumah tangga $(33,1 \%)$ yang memanfaatkan penampungan/peresapan sebagai tempat pembuangan air limbah, terdapat 116 rumah tangga $(70,7 \%)$ yang memiliki Tempat Pembuangan sampah dan masih terdapat sumber air bersih yang berjarak $\leq 10$ meter sebanyak 66 rumah tangga $(38,0 \%)$, disarankan agar menjalin kerjasama lintas sektoral antara pemerintah, Puskesmas dan sektor terkait lainnya dengan masyarakat untuk meningkatkan cakupan dan kesadaran masyarakat terhadap jamban keluarga, SPAL, tempat sampah dan sumber air bersih yang memenuhi syarat di Desa Kramat Kecamatan Tapa Kabupaten Bone Bolango.

\section{DAFTAR PUSTAKA}

[1] Desa Kramat.. Profil Desa. Gorontalo; 2016

[2] Kementerian Kesehatan. Riskesdas, 2013. Jakarta; 2103

[3] Notoatmodjo, S. Ilmu Kesehatan Masyarakat (Prinsip-Prinsip Dasar). Jakarta: PT Rineka Cipta. 2003 ..Kesehatan Masyarakat Ilmu dan Seni. Jakarta: PT Rineka Cipta; 2007 